\title{
A study on chemical constituents and sugars extraction from spent coffee grounds
}

\author{
Solange I. Mussatto ${ }^{\mathrm{a}, *}$, Livia M. Carneiro ${ }^{\mathrm{b}}$, João P.A. Silva ${ }^{\mathrm{b}}$, Inês C. Roberto ${ }^{\mathrm{b}}$, José A. Teixeira ${ }^{\mathrm{a}}$ \\ a IBB - Institute for Biotechnology and Bioengineering, Centre of Biological Engineering, University of Minho, Campus de Gualtar, 4710-057 Braga, Portugal \\ ${ }^{\mathrm{b}}$ Department of Biotechnology, Engineering College of Lorena, University of São Paulo, Estrada Municipal do Campinho s/n, $12602-810$ Lorena/SP, Brazil
}

\section{A R T I C L E I N F O}

\section{Article history:}

Received 12 July 2010

Received in revised form 26 July 2010

Accepted 27 July 2010

Available online 6 August 2010

\section{Keywords:}

Spent coffee grounds

Chemical composition

Hemicellulose

Dilute acid hydrolysis

Experimental design

\begin{abstract}
A B S T R A C T
Spent coffee grounds (SCG), the residual materials obtained during the processing of raw coffee powder to prepare instant coffee, are the main coffee industry residues. In the present work, this material was chemically characterized and subsequently submitted to a dilute acid hydrolysis aiming to recover the hemicellulose sugars. Reactions were performed according to experimental designs to verify the effects of the variables $\mathrm{H}_{2} \mathrm{SO}_{4}$ concentration, liquid-to-solid ratio, temperature, and reaction time, on the efficiency of hydrolysis. SCG was found to be rich in sugars ( $45.3 \%, \mathrm{w} / \mathrm{w})$, among of which hemicellulose (constituted by mannose, galactose, and arabinose) and cellulose (glucose homopolymer) correspond to $36.7 \%(\mathrm{w} / \mathrm{w})$ and $8.6 \%(\mathrm{w} / \mathrm{w})$, respectively. Optimal conditions for hemicellulose sugars extraction consisted in using $100 \mathrm{mg}$ acid/g dry matter, $10 \mathrm{~g}$ liquid/g solid, at $163^{\circ} \mathrm{C}$ for $45 \mathrm{~min}$. Under these conditions, hydrolysis efficiencies of $100 \%, 77.4 \%$, and $89.5 \%$ may be achieved for galactan, mannan, and arabinan, respectively, corresponding to a hemicellulose hydrolysis efficiency of $87.4 \%$.
\end{abstract}

(c) 2010 Elsevier Ltd. All rights reserved.

\section{Introduction}

Coffee is one of the world's most widely consumed beverages, and spent coffee grounds (SCG), the solid residues obtained from the treatment of coffee powder with hot water to prepare instant coffee, are the main coffee industry residues with a worldwide annual generation of 6 million tons (Tokimoto, Kawasaki, Nakamura, Akutagawa, \& Tanada, 2005). Considering this huge amount of coffee residue produced all over the world, the reutilization of this material is a relevant subject. Some attempts for reutilization of SCG have been made, using it as fuel in industrial boilers of the same industry due to its high calorific power of about $5000 \mathrm{kcal} / \mathrm{kg}$ (Silva, Nebra, Silva, \& Sanchez, 1998), as an antioxidant material source (Yen, Wang, Chang, \& Duh, 2005), or as a source of polysaccharide with immunostimulatory activity (Simões et al., 2009). Kondamudi, Mohapatra, and Misra (2008) demonstrated that SCG can be used for the production of biodiesel and fuel pellets. SCG was also considered an inexpensive and easily available adsorbent for the removal of cationic dyes in wastewater treatments (Franca, Oliveira, \& Ferreira, 2009). However, none of these strategies have yet been routinely implemented, and most of these residues remain unutilized, being discharged to the environment where they cause severe contamination and environmental pollu-

\footnotetext{
* Corresponding author. Tel.: +351 253604 424; fax: +351 253678986. E-mail addresses: solange@deb.uminho.pt, solangemussatto@hotmail.com (S.I. Mussatto).
}

tion problems due to the toxic nature (presence of caffeine, tannins, and polyphenols) (Leifa, Pandey, \& Soccol, 2000). Nowadays, there is great political and social pressure to reduce the pollution arising from industrial activities. In this sense, conversion of SCG to value-added compounds is of environmental and economical interest.

Hemicelluloses, the second most common polysaccharides in nature, are heterogeneous polymers of pentoses (xylose and arabinose), hexoses (mannose, galactose, glucose), and sugar acids. In recent years, bioconversion of hemicellulose has received much attention because of its practical applications in various industrial processes, such as for the production of fuels and chemicals (Saha, 2003). Hemicelluloses are usually found in the nature in association with other polymeric fractions, namely the cellulose and lignin. To be efficiently used in bioconversion processes, the hemicellulose polysaccharide needs to be separated from these other structures. Different processes may be used for this purpose, among of which, dilute acid hydrolysis stands out as one of the most efficient to selectively release hemicellulose sugars (Mussatto \& Roberto, 2004). The major problem of acid hydrolysis is that the decomposition of monomeric sugars produced during the reaction takes place simultaneously with the hydrolysis of polysaccharides. To prevent sugars decomposition, it is very important to conduct the process under adequate reaction conditions. The experimental design statistical methodology is a useful tool to define such conditions performing a minimal number of experiments. This methodology has been employed in several works to maximize the sugars recovery from agro-industrial residues through the establishment of the 
Table 1

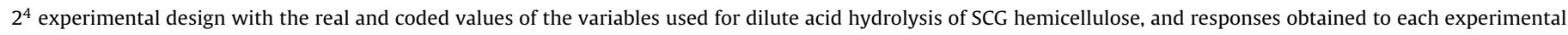
condition.

\begin{tabular}{|c|c|c|c|c|c|c|c|c|c|c|c|c|c|}
\hline \multirow[t]{3}{*}{ Assay } & \multirow{2}{*}{\multicolumn{4}{|c|}{$\frac{\text { Variables }}{\text { Real values (coded values) }}$}} & \multicolumn{9}{|c|}{ Responses } \\
\hline & & & & & \multicolumn{5}{|c|}{ Sugars $(\mathrm{g} / \mathrm{l})^{\mathrm{b}}$} & \multicolumn{4}{|c|}{ Efficiencies (\%) } \\
\hline & $X_{1}$ & $X_{2}$ & $X_{3}$ & $X_{4}$ & Cel & Glu & Arab & Gal & Man & $\eta_{\text {Gal }}$ & $\eta_{\text {Man }}$ & $\eta_{\text {Arab }}$ & $\eta_{\text {Hemi }}$ \\
\hline 1 & $10(-1)$ & $100(-1)$ & $15(-1)$ & $100(-1)$ & 0 & 0 & 0.08 & 0 & 0 & 0 & 0 & 4.8 & 0.2 \\
\hline 2 & $14(+1)$ & $100(-1)$ & $15(-1)$ & $100(-1)$ & 0.03 & 0 & 0.06 & 0 & 0 & 0 & 0 & 4.8 & 0.2 \\
\hline 3 & $10(-1)$ & $140(+1)$ & $15(-1)$ & $100(-1)$ & 0 & 0 & 0.13 & 0 & 0 & 0 & 0 & 7.8 & 0.4 \\
\hline 4 & $14(+1)$ & $140(+1)$ & $15(-1)$ & $100(-1)$ & 0.05 & 0 & 0.05 & 0 & 0 & 0 & 0 & 4.2 & 0.2 \\
\hline 5 & $10(-1)$ & $100(-1)$ & $45(+1)$ & $100(-1)$ & 0.01 & 0.06 & 1.32 & 0.15 & 0.11 & 1.2 & 0.6 & 79.8 & 4.6 \\
\hline 6 & $14(+1)$ & $100(-1)$ & $45(+1)$ & $100(-1)$ & 0 & 0 & 1.03 & 0.07 & 0.34 & 0.8 & 2.4 & 87.4 & 5.9 \\
\hline 7 & $10(-1)$ & $140(+1)$ & $45(+1)$ & $100(-1)$ & 0.05 & 0.11 & 1.85 & 0.27 & 0.13 & 2.1 & 0.7 & 100.0 & 6.0 \\
\hline 8 & $14(+1)$ & $140(+1)$ & $45(+1)$ & $100(-1)$ & 0 & 0 & 1.04 & 0.07 & 0.09 & 0.8 & 0.6 & 88.2 & 4.9 \\
\hline 9 & $10(-1)$ & $100(-1)$ & $15(-1)$ & $140(+1)$ & 0.14 & 0.27 & 1.96 & 0.68 & 0.30 & 5.3 & 1.5 & 100.0 & 7.7 \\
\hline 10 & $14(+1)$ & $100(-1)$ & $15(-1)$ & $140(+1)$ & 0 & 0 & 0.87 & 0.11 & 0.11 & 1.2 & 0.8 & 73.8 & 4.5 \\
\hline 11 & $10(-1)$ & $140(+1)$ & $15(-1)$ & $140(+1)$ & 0.10 & 0.09 & 1.91 & 0.51 & 0.24 & 4.0 & 1.2 & 100.0 & 7.0 \\
\hline 12 & $14(+1)$ & $140(+1)$ & $15(-1)$ & $140(+1)$ & 0.02 & 0 & 1.11 & 0.18 & 0.13 & 2.0 & 0.9 & 94.2 & 5.8 \\
\hline 13 & $10(-1)$ & $100(-1)$ & $45(+1)$ & $140(+1)$ & 0 & 0.28 & 2.12 & 14.26 & 11.24 & 100.0 & 56.6 & 100.0 & 74.9 \\
\hline 14 & $14(+1)$ & $100(-1)$ & $45(+1)$ & $140(+1)$ & 0.21 & 1.08 & 1.79 & 5.12 & 4.68 & 55.8 & 33.1 & 100.0 & 44.8 \\
\hline 15 & $10(-1)$ & $140(+1)$ & $45(+1)$ & $140(+1)$ & 0 & 0.25 & 2.54 & 13.64 & 14.31 & 100.0 & 72.1 & 100.0 & 83.9 \\
\hline 16 & $14(+1)$ & $140(+1)$ & $45(+1)$ & $140(+1)$ & 0.11 & 0.94 & 2.06 & 9.45 & 4.74 & 100.0 & 33.5 & 100.0 & 61.6 \\
\hline 17 & $12(0)$ & $120(0)$ & $30(0)$ & $120(0)$ & 0.10 & 0.13 & 1.79 & 0.59 & 0.21 & 5.5 & 1.3 & 100.0 & 7.6 \\
\hline 18 & $12(0)$ & $120(0)$ & $30(0)$ & $120(0)$ & 0.09 & 0.09 & 1.67 & 0.43 & 0.19 & 4.0 & 1.2 & 100.0 & 7.0 \\
\hline 19 & $12(0)$ & $120(0)$ & $30(0)$ & $120(0)$ & 0.08 & 0.08 & 1.64 & 0.43 & 0.18 & 4.0 & 1.1 & 100.0 & 6.9 \\
\hline
\end{tabular}

a $X_{1}$ : liquid-to-solid ratio $(\mathrm{g} / \mathrm{g}) ; X_{2}$ : acid concentration $(\mathrm{mg} / \mathrm{g}) ; X_{3}$ : reaction time $(\mathrm{min}) ; X_{4}$ : temperature $\left({ }^{\circ} \mathrm{C}\right)$.

b Cel: cellobiose; Glu: glucose; Arab: arabinose; Gal: galactose; Man: mannose.

c $\eta$ : efficiency of hydrolysis; Hemi: hemicellulose.

best hydrolysis operational conditions (Mussatto \& Roberto, 2005; Neureiter et al., 2004; Roberto, Mussatto, \& Rodrigues, 2003).

In view of the aforementioned, the present work evaluated the sugars extraction from SCG hemicellulose, as a first step to explore the use of this material in fermentative processes. Initially, the material was chemically characterized, and its hemicellulose content was determined. In a subsequent stage, extraction reactions were performed by using dilute acid under different operational conditions (liquid-to-solid ratio, acid concentration, reaction time and temperature), which were proposed according to experimental designs. The condition able to maximize the extraction results was established by statistical analysis.

\section{Material and methods}

\subsection{Raw material characterization}

Spent coffee grounds (SCG) were supplied by NovaDeltaComércio e Indústria de Cafés, S.A. (Campo Maior, Portugal). The material with around $80 \%$ humidity was dried at $60 \pm 5^{\circ} \mathrm{C}$ to $10 \%$ moisture content, being thus stored until be required for processing or analysis.

For chemical characterization, dried SCG was subjected to a quantitative acid hydrolysis with $72 \%(\mathrm{w} / \mathrm{w})$ sulfuric acid. In this method, $2 \mathrm{~g}$ of sample were first added to $10 \mathrm{ml} 72 \% \mathrm{H}_{2} \mathrm{SO}_{4}$ and maintained at $50^{\circ} \mathrm{C}$ for $7 \mathrm{~min}$. After this pre-treatment, distilled water was added to the mixture to dilute the $\mathrm{H}_{2} \mathrm{SO}_{4}$ to $1 \mathrm{~N}$, and incubated at $121^{\circ} \mathrm{C}$ for $45 \mathrm{~min}$. The monosaccharides and acetic acid contained in hydrolysates were determined by HPLC in order to estimate the contents of samples in cellulose (as glucan), hemicellulose (as mannan + galactan + arabinan + xylan) and acetyl groups. Protein content was estimated by the Kjeldahl nitrogen method, and a factor of 6.25 was used to convert nitrogen into protein. Ashes were determined by weight difference before and after incineration of the SCG sample in a muffle furnace at $550^{\circ} \mathrm{C}$ for $4 \mathrm{~h}$. Before weighing, samples were placed in a desiccator for $50 \mathrm{~min}$. The mineral content was determined by Inductively Coupled Plasma Atomic Emission Spectrometry (ICP-AES). All determinations were carried out in triplicate.

\subsection{Dilute acid hydrolysis}

Dried SCG was submitted to hydrolysis reactions under different conditions of $\mathrm{H}_{2} \mathrm{SO}_{4}$ concentration (100-140 mg/g dry matter), liquid-to-solid ratio $(10-14 \mathrm{~g} / \mathrm{g})$, temperature $\left(100-180^{\circ} \mathrm{C}\right)$, and reaction time (15-75 $\mathrm{min})$, which were combined as proposed in experimental designs. For the experiments, SCG and the required amount of acid solution were placed in $200-\mathrm{ml}$ stainless steel batch cylindrical reactors. Under the desired temperature, the dully covered reactors were introduced into a silicone oil bath where they were maintained during the necessary time. At the end of each reaction, the reactors were immediately cooled in ice bath, and the resulting solid material was separated by filtration. The filtrates (hemicellulosic hydrolysates) were analyzed for sugars (cellobiose, glucose, arabinose, mannose, galactose, and xylose), degradation products (furfural, hydroxymethylfurfural, and total phenols), and acetic acid determination.

\subsection{Experimental designs}

Initially, a $2^{4}$ full-factorial design with three levels leading to 19 sets of experiments was made to evaluate the effect of four variables, namely the liquid-to-solid ratio $\left(X_{1}\right)$, acid concentration $\left(X_{2}\right)$, reaction time $\left(X_{3}\right)$, and temperature $\left(X_{4}\right)$, on the hydrolysis of SCG hemicellulose. For statistical analysis, the variables were coded according to Eq. (1), where each independent variable is represented by $x_{i}$ (coded value), $X_{i}$ (real value), $X_{0}$ (real value at the center point), and $\Delta X_{i}$ (step change value). The levels of the variables investigated in this study are given in Table 1 . Three assays in the center point were carried out to estimate the random error needed for the analysis of variance, as well as to examine the presence of curvature in the response surfaces. Hydrolysis efficiency of galactan, mannan, arabinan, and hemicellulose were taken as responses of the design experiments.

$x_{i}=\frac{X_{i}-X_{0}}{\Delta X_{i}}$

Based on the results obtained in the $2^{4}$ design, a $2^{2}$ central composite design was proposed to maximize the sugars recovery from 
Table 2

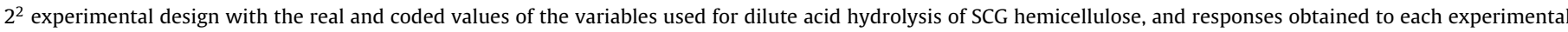
condition.

\begin{tabular}{|c|c|c|c|c|c|c|c|c|c|c|c|}
\hline \multirow[t]{3}{*}{ Assay } & \multirow{2}{*}{\multicolumn{2}{|c|}{$\frac{\text { Variables }}{\text { Real values (coded values) }}$}} & \multicolumn{9}{|c|}{ Responses } \\
\hline & & & \multicolumn{5}{|c|}{ Sugars $(\mathrm{g} / \mathrm{l})^{\mathrm{b}}$} & \multicolumn{4}{|c|}{ Efficiencies (\%) ${ }^{c}$} \\
\hline & $X_{3}$ & $X_{4}$ & Cel & Glu & Arab & Gal & Man & $\eta_{\text {Gal }}$ & $\eta_{\text {Man }}$ & $\eta_{\text {Arab }}$ & $\eta_{\text {Hemi }}$ \\
\hline 1 & $45(-1)$ & $140(-1)$ & 0 & 0.29 & 1.68 & 12.56 & 8.58 & 94.9 & 41.9 & 98.2 & 64.5 \\
\hline 2 & $75(+1)$ & $140(-1)$ & 0 & 0.25 & 1.93 & 14.77 & 13.55 & 100.0 & 66.2 & 100.0 & 80.5 \\
\hline 3 & $45(-1)$ & $180(+1)$ & 0 & 0.96 & 1.32 & 12.78 & 13.30 & 96.3 & 65.0 & 77.7 & 77.3 \\
\hline 4 & $75(+1)$ & $180(+1)$ & 0 & 1.51 & 0.50 & 9.00 & 6.34 & 67.8 & 31.0 & 29.4 & 44.7 \\
\hline 5 & $60(0)$ & $160(0)$ & 0 & 0.43 & 1.67 & 15.18 & 16.23 & 100.0 & 79.3 & 98.2 & 88.0 \\
\hline 6 & $60(0)$ & $160(0)$ & 0 & 0.39 & 1.99 & 14.47 & 16.73 & 100.0 & 81.7 & 100.0 & 89.5 \\
\hline 7 & $45(-1)$ & $160(0)$ & 0 & 0.38 & 1.67 & 15.91 & 15.66 & 100.0 & 76.5 & 98.2 & 86.4 \\
\hline 8 & $75(+1)$ & $160(0)$ & 0 & 0.61 & 0.82 & 14.32 & 13.02 & 100.0 & 63.6 & 48.2 & 76.5 \\
\hline 9 & $60(0)$ & $140(-1)$ & 0 & 0.22 & 1.90 & 14.14 & 9.87 & 100.0 & 48.2 & 100.0 & 70.1 \\
\hline 10 & $60(0)$ & $180(+1)$ & 0 & 1.18 & 0.80 & 12.19 & 9.58 & 91.8 & 46.8 & 47.1 & 63.7 \\
\hline
\end{tabular}

${ }^{\text {a }} X_{3}$ : reaction time $(\min ) ; X_{4}$ : temperature $\left({ }^{\circ} \mathrm{C}\right)$.

b Cel: cellobiose; Glu: glucose; Arab: arabinose; Gal: galactose; Man: mannose.

c $\eta$ : efficiency of hydrolysis; Hemi: hemicellulose.

SCG hemicellulose. This new design, leading to additional 10 sets of experiments, was made to evaluate the effect of the previously selected variables: temperature and reaction time, in the range of values given in Table 2. Acid concentration and liquid-to-solid ratio were fixed in these assays in $100 \mathrm{mg} / \mathrm{g}$, and $14 \mathrm{~g} / \mathrm{g}$, respectively.

The experimental results were fitted with second-order polynomial equations by multiple regression analyses. The quadratic models were expressed according to Eq. (2), where $\hat{y}_{i}$ represents the response variable, $b_{0}$ is the interception coefficient, $b_{i}, b_{i i}$ and $b_{i j}$ are the regression coefficients, $n$ is the number of studied variables, and $X_{i}$ and $X_{j}$ represent the independent variables. Where possible, the models were simplified by elimination of statistically insignificant terms.

$\hat{y}_{i}=b_{0}+\sum_{i=1}^{n} b_{i} X_{i}+\sum_{i=1}^{n} b_{i i} X_{i}^{2}+\sum_{i=1}^{n-1} \sum_{j=i+1}^{n} b_{i j} X_{i} X_{j}$

Statistical significance of the regression coefficients was determined by Student's $t$-test, and the proportion of variance explained by the models were given by the multiple coefficient of determination, $R^{2}$. Results were analyzed by using the softwares Statistica version 5.0, and Design Expert version 5.0.

\subsection{Analytical methodology}

Glucose, arabinose, mannose, galactose, xylose, cellobiose, acetic acid, furfural and hydroxymethylfurfural concentrations were determined by high-performance liquid chromatography (HPLC) on a Jasco chromatograph. For sugars determination, a refractive index detector and a Varian column Metacarb 87P $(300 \mathrm{~mm} \times 7.8 \mathrm{~mm})$ at $80^{\circ} \mathrm{C}$ were used. Ultrapure water was used as eluent at a flow rate of $0.4 \mathrm{ml} / \mathrm{min}$. Acetic acid concentration was also determined in a refractive index detector, but using a Bio-Rad Aminex HPX-87H $(300 \mathrm{~mm} \times 7.8 \mathrm{~mm})$ column at $60^{\circ} \mathrm{C}$, and sulfuric acid $0.005 \mathrm{M}$ as eluent at a flow rate of $0.7 \mathrm{ml} / \mathrm{min}$. Furfural and hydroxymethylfurfural were determined with a UV detector (at $280 \mathrm{~nm})$ and a Nucleosil 120-5 C18 $5 \mu \mathrm{m}(4.6 \mathrm{~mm} \times 250 \mathrm{~mm})$ column at room temperature, using acetonitrile/water ( $1 / 8$ with $10 \mathrm{~g} / \mathrm{l}$ acetic acid) as the eluent at a flow rate of $0.8 \mathrm{ml} / \mathrm{min}$. In all the cases, a sample volume of $20 \mu \mathrm{l}$ was injected.

For total phenols determination, the $\mathrm{pH}$ of the hydrolysate samples was raised to 12.0 with $\mathrm{NaOH} 6.0 \mathrm{M}$ and the resulting solution was diluted with distilled water in order to obtain an absorbance reading not exceeding 0.5 . The phenols concentration was then calculated according to Eqs. (3) and (4), where TP is the total phenols concentration $(\mathrm{g} / \mathrm{l}), A_{\mathrm{LIG} 280}$ is the absorbance reading at
$280 \mathrm{~nm}$ after dilution's correction, $C_{\mathrm{F}}$ and $C_{\mathrm{HMF}}$ are the concentrations $(\mathrm{g} / \mathrm{l})$ of furfural and hydroxymethylfurfural determined by HPLC, and $\varepsilon_{\mathrm{F}}$ and $\varepsilon_{\mathrm{HMF}}$ are the extinction coefficients $(1 / \mathrm{g} \mathrm{cm})$ of furfural (146.85) and HMF (114.00) previously determined by ultraviolet spectroscopy at $280 \mathrm{~nm}$.

$\mathrm{TP}=4.187 \times 10^{-2}\left(A_{\mathrm{LIG} 280}-A_{\mathrm{PD} 280}\right)-3.279 \times 10^{-4}$

$A_{\mathrm{PD} 280}=\left[\left(C_{F} \varepsilon_{F}\right)+\left(C_{H M F} \varepsilon_{H M F}\right)\right]$

The recovered sugar yield $\left(Y_{\mathrm{S}}\right.$, in gram of substance that can be achieved from $100 \mathrm{~g}$ of SCG dry matter), and the hydrolysis efficiency $(\eta, \%)$ were calculated using Eqs. (5) and (6), respectively, where $C$ is the concentration of the component in the liquid phase $(\mathrm{g} / \mathrm{l}) ; M$ is the amount of SCG (dry matter) employed in the experiment (g); $V$ is the volume of liquid solution employed (1) and $Y_{\max }$ is the maximum yield in recovered sugars that can be attained ( $\mathrm{g}$ per $100 \mathrm{~g}$ dry matter).

$Y_{\mathrm{S}}=\left(C \times \frac{V}{M}\right) \times 100$

$\eta=\left(\frac{Y_{\mathrm{S}}}{Y_{\max }}\right) \times 100$

\section{Results and discussion}

\subsection{Chemical composition of SCG}

Carbohydrates are the most important constituents in coffee beans (Arya \& Rao, 2007), and similarly in SCG. As can be seen in Table 3, SCG is a residue rich in sugars polymerized into cellulose and hemicellulose structures, which correspond to almost half of material dry weight $(45.3 \%, \mathrm{w} / \mathrm{w})$. Hemicellulose is composed by three sugars, mannose being the most abundant, followed by galactose and few quantities of arabinose (mannan:galactan and galactan:arabinan ratios of 1.54 and 8.12, respectively). Xylose was not found in SCG composition. These results are in agreement with observations made by other authors that polysaccharides in coffee cell wall are constituted by mannose, galactose, arabinose and glucose sugars, forming mainly galactomannan, arabinogalactan and cellulose structures (Arya \& Rao, 2007; Fischer, Reimann, Trovato, \& Redgwell, 2001; Oosterveld, Harmsen, Voragen, \& Schols, 2003; Redgwell, Curti, Fischer, Nicolas, \& Fay, 2002). Sugars composition in SCG was found to be $46.8 \%$ mannose, followed by $30.4 \%$ galactose, $19.0 \%$ glucose, and $3.8 \%$ arabinose, revealing mannans as the major polysaccharides in this residue. These values are a bit different from those reported by Simões et al. (2009), who reported the presence of mannose (57\%), followed by galactose (26\%), glucose $(11 \%)$ and 
Table 3

Chemical composition of spent coffee grounds.

\begin{tabular}{lc}
\hline Components & Dry weight $(\mathrm{g} / 100 \mathrm{~g})$ \\
\hline Cellulose (glucan) & 8.6 \\
Hemicellulose & 36.7 \\
Arabinan & 1.7 \\
Galactan & 13.8 \\
Mannan & 21.2 \\
Proteins $(N \times 6.25)$ & 13.6 \\
Acetyl groups & 2.2 \\
Ashes & 1.6 \\
& \\
Minerals & $(\mathrm{mg} / \mathrm{kg})$ \\
\hline Potassium & 3549.0 \\
Phosphorus & 1475.1 \\
Magnesium & 1293.3 \\
Calcium & 777.4 \\
Aluminum & 279.3 \\
Iron & 118.7 \\
Manganese & 40.1 \\
Copper & 32.3 \\
Zinc & 15.1 \\
Sulfur & nd \\
Chromium & nd \\
\hline
\end{tabular}

nd: not detected.

arabinose (6\%). In fact, differences in the chemical composition of SCG may occur according to the variety of beans utilized, and the roasting and extraction processes that they were submitted.

In addition to polysaccharides, SCG also contains significant protein content (13.6\% w/w) (Table 3). According to Arya and Rao (2007), roasted coffee contains on average $3.1 \%(w / w)$ protein. During the process with water for the instant coffee prepare, many of the other grain components are extracted, and as a consequence, the non-extracted components have their proportion concentrated in the residual solid material. Therefore, the protein content is higher in SCG than in the coffee grains. It must be emphasized that as the protein content in SCG was calculated from the total nitrogen content of the samples, it may have been overestimated due to the presence of other nitrogen-containing substances (caffeine, trigonelline, free amines and amino acids) (Delgado, Vignoli, Siikaaho, \& Franco, 2008). Even so, the value here found was close to the value reported by Ravindranath, Yousuf Ali Khan, Oby Reddy, Thirumala Rao, \& Reddy (1972), which was of about $14 \%$, but was higher than the value reported by Lago, Antoniassi, \& Freitas (2001), which varied between $6.7 \%$ and $9.9 \%$.

Protein-bound amino acids were not quantified in the present work, but some authors have reported that SCG contains the following amino acids (range of values, $\mathrm{mg} / 100 \mathrm{~g}$ ): aspartic acid (10-137), glutamic acid (618-987), serine (46-85), histidine (7-378), glycine (131-567), threonine (18-160), alanine (260-388), arginine (8-13), tyrosine (152-288), cystine (281-362), valine (324-488), methionine (53-136), phenylalanine (29-477), isoleucine (275-377), leucine (567-779), lysine (100-164), and proline (169-338) (Lago et al., 2001).

SCG also contains ashes, which, according to the ICP-AES analysis, are constituted by several minerals. Potassium is the most abundant element, followed by phosphorus and magnesium (Table 3). Potassium is also the most abundant element in coffee beans, corresponding to $40 \%$ of the oxide ash (Arya \& Rao, 2007). After extraction with hot water for the instant coffee prepare, most of the mineral elements are easily extracted (Arya \& Rao, 2007), but SCG still contains potassium as predominant.

\subsection{Hemicellulose sugars extraction from SCG}

Table 1 shows the experimental results obtained according to the $2^{4}$ experimental design. It can be noted that sugars were

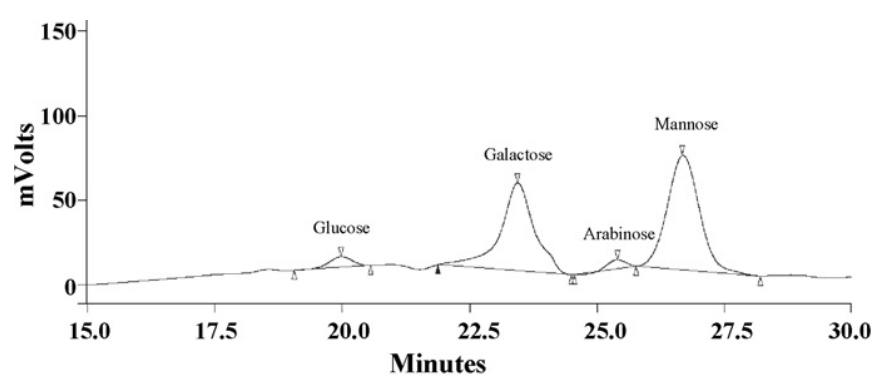

Fig. 1. Chromatogram profile of sugars solubilized from spent coffee grounds acid hydrolysis.

extracted in all the used reaction conditions, but the concentration values of them varied to each assay. The chromatogram profile shown in Fig. 1 reveals glucose, arabinose, mannose and galactose as the only sugars present in SCG hydrolysate that is in agreement with the chemical composition previously presented. Cellobiose (a glucose dimer connected by a glycosidic bond) and glucose were liberated in low amounts in all the assays, demonstrating that the used reaction conditions were not suitable for the cellulose hydrolysis, but only for the hemicellulose hydrolysis, which was the objective of the present work. In fact, cellulose hydrolysis requires the use of more severe conditions of acid concentration, temperature and reaction time than those here used (Mussatto \& Roberto, 2004). For the conditions that promoted the highest hemicellulose hydrolysis efficiencies ( $>60 \%$, Table 1 ), galactose and mannose were the most abundant sugars present in the produced hydrolysates, that is in accordance to the chemical composition previously determined, which revealed that galactan and mannan are the main sugars polymers present in SCG.

As a consequence of the differences in the sugars extraction, different hydrolysis efficiency values were achieved, varying between $0 \%$ and $100 \%$ for galactan, 0 and $72.1 \%$ for mannan, 4.2 and $100 \%$ for arabinan and 0.2 and $83.9 \%$ for the overall hydrolysis of hemicellulose (Table 1). Arabinose was the sugar more easily released from the hemicellulose structure, since it was totally extracted in 10 of the 19 evaluated hydrolysis conditions. Even in the mildest reaction condition (assay 1), arabinose was detected in the produced hydrolysate, and no other sugar was found. Galactose was totally released in 3 of the studied conditions, suggesting that galactan in SCG has a major susceptibility to hydrolysis than the mannan structure, which was not totally hydrolysed in any of the performed assays. In fact, arabinogalactans dissolve better than linear mannans, and one of the reasons for this is the association of linear mannans to form crystalline regions (Bradbury \& Atkins, 1997). In addition, in a polymeric structure, side chains are more easily released than the main chains. Arabinogalactans in SCG consist of a main chain of $1 \rightarrow 3$ linked galactose branched at C-6, with side chains containing arabinose and galactose. Galactomannans consist of a main chain of $1 \rightarrow 4$ linked mannan with galactose unit side chains linked at C-6, and different degrees of branching (Bradbury \& Halliday, 1990; Navarini et al. (1999); Nunes, Reis, Domingues, \& Coimbra, 2006). Such fact explains the major difficult in extract mannose than galactose or arabinose from the SCG hemicellulose.

A statistical analysis of the efficiency results was then performed. The Pareto charts shown in Fig. 2 represent the estimated effects of the variables used during the dilute acid hydrolysis on the efficiency responses. The length of each bar was proportional to the standardized effect. Bars extending beyond the vertical line corresponded to effects statistically significant at $95 \%$ confidence level. This analysis revealed positive and significant effects of temperature and reaction time, as well as the interaction between these variables, in all the evaluated responses. Such effects suggest that sugars extraction was higher when the temperature and reac- 

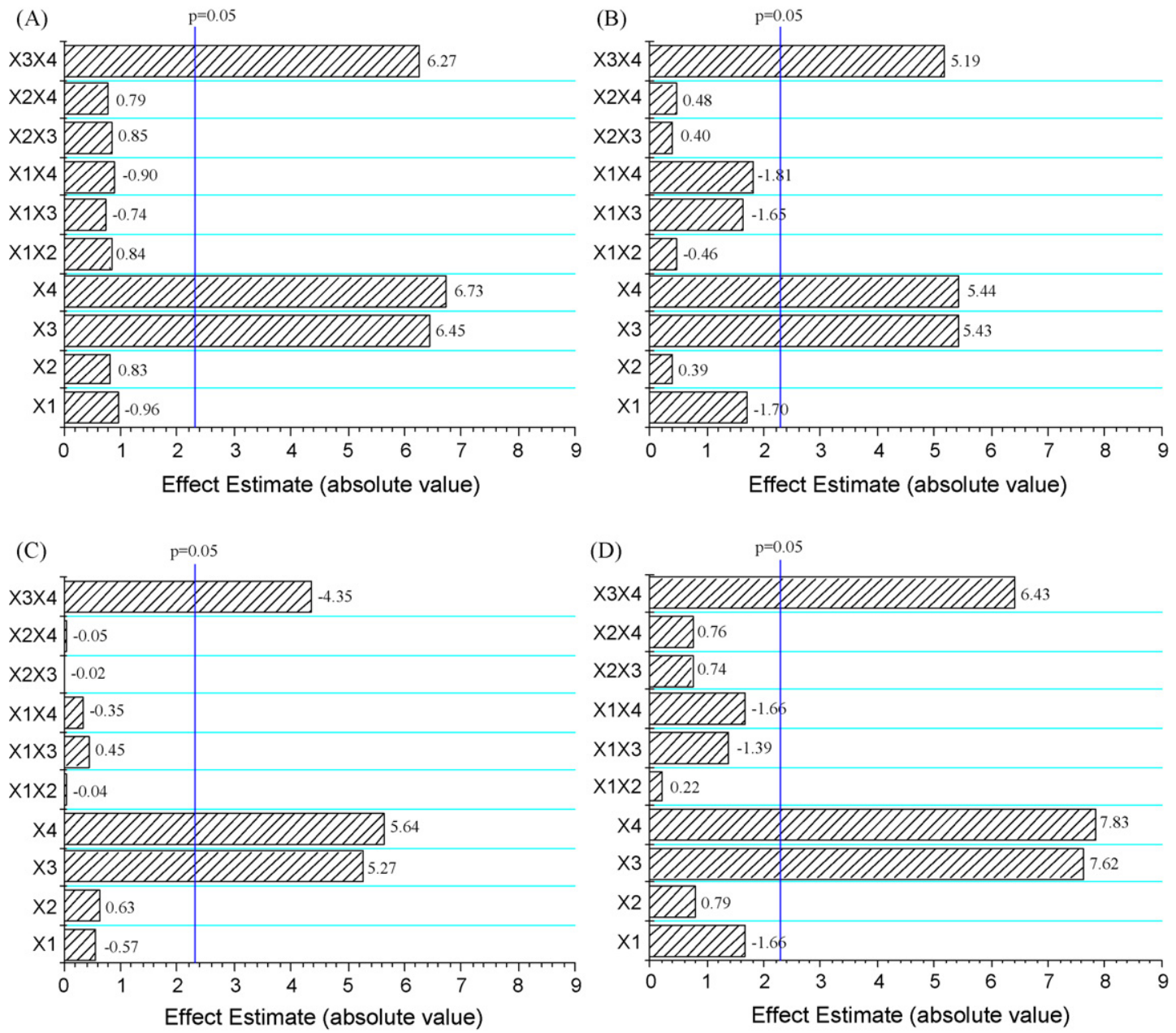

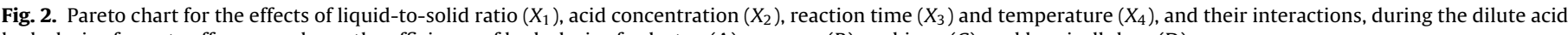
hydrolysis of spent coffee grounds, on the efficiency of hydrolysis of galactan (A), mannan (B), arabinan (C), and hemicellulose (D).

tion time used for dilute acid hydrolysis were increased. The other two variables, acid concentration and liquid-to-solid ratio, did not show significant influence on the responses at 95\% confidence level.

Since mannose, the main sugar present in SCG was not fully extracted under the evaluated conditions; additional hydrolysis assays were performed aiming to improve the extraction of this sugar. In this step, a $2^{2}$ full-factorial design was used to determine the best conditions of temperature and reaction time to be used on SCG hydrolysis. Acid concentration and liquid-to-solid ratio were fixed at the lowest levels used in the first design. The experimental results obtained in these assays are shown in Table 2 . When comparing these results with those achieved in the $2^{4}$ experimental design (Table 1 ) it is evident that the sugars extractions and the hydrolysis efficiencies results were improved due to the use of this higher range of values for temperature and reaction time. The efficiency of hydrolysis of galactan, for example, attained the maximum value for 6 of the 10 evaluated conditions. Efficiency of hydrolysis of mannan was increased to $81.7 \%$ and resulted in a total efficiency of hemicellulose hydrolysis of about $90 \%$ (assay 6). Otherwise, the efficiency of hydrolysis of arabinan, which had attained the maximum value in most of the experiments of the first design, was only maximum in three of the evaluated conditions (Table 2). Probably, some degradation of the released arabinose occurred in these experiments, giving thus efficiency results lower than $100 \%$. Therefore, the arabinose efficiency results lower than 100\% does not mean that this sugar was not fully released from the hemi- cellulose structure, but it was probably released and subsequently degraded.

In fact, when analyzing the concentration of toxic compounds in the hydrolysates, it can be noted that elevated values of furfural were obtained according to the used reaction conditions (Table 4). Furfural is a by-product generated from the degradation of pentose sugars, like arabinose (Mussatto \& Roberto, 2004). In the first experimental design, the highest furfural concentration obtained was $0.06 \mathrm{~g} / \mathrm{l}$, while in the second experimental design, a value of $3.93 \mathrm{~g} / \mathrm{l}$ was found in the hydrolysate produced under the highest temper-

\section{Table 4}

Concentration of toxic compounds in the hydrolysates produced from SCG under different operational conditions, according to the $2^{2}$ full-factorial design.

\begin{tabular}{cllll}
\hline Assay & \multicolumn{4}{l}{ Toxic compounds $(\mathrm{g} / \mathrm{l})$} \\
\cline { 2 - 5 } & Acetic acid & Furfural & HMF $^{\mathrm{a}}$ & Total phenols \\
\hline 1 & 0.74 & 0.06 & 0.01 & 4.08 \\
2 & 0.79 & 0.14 & 0.04 & 4.68 \\
3 & 0.93 & 2.81 & 0.37 & 5.48 \\
4 & 1.36 & 3.93 & 0.49 & 1.42 \\
5 & 0.83 & 0.91 & 0.14 & 5.24 \\
6 & 0.82 & 0.81 & 0.13 & 5.13 \\
7 & 0.81 & 0.69 & 0.11 & 3.51 \\
8 & 0.90 & 2.42 & 0.35 & 3.45 \\
9 & 0.76 & 0.10 & 0.02 & 4.15 \\
10 & 1.03 & 3.56 & 0.55 & 1.82 \\
\hline
\end{tabular}

a HMF: hydroxymethylfurfural. 
(A)

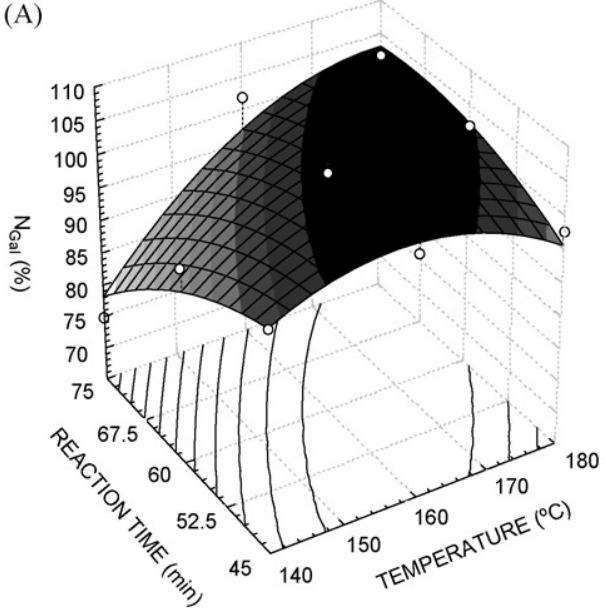

(C)

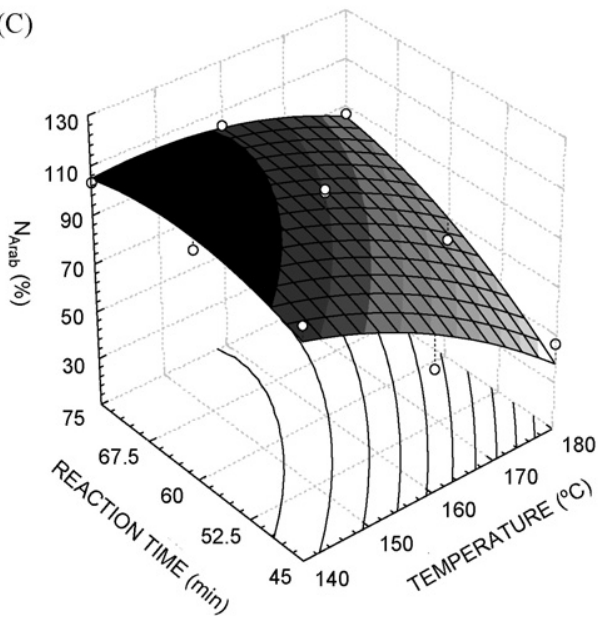

(B)

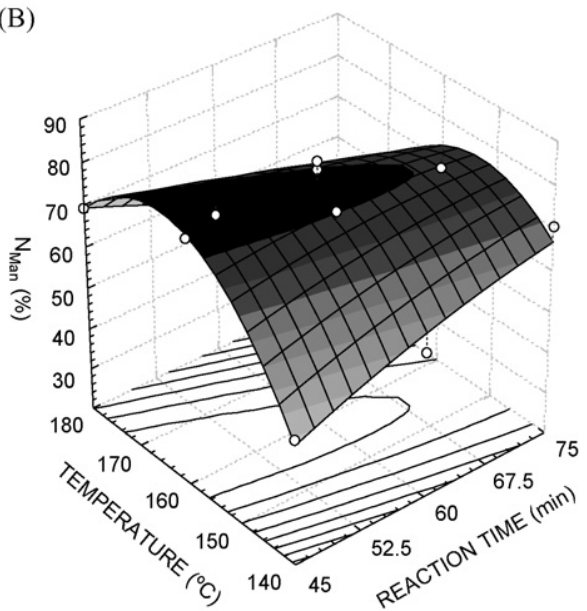

(D)

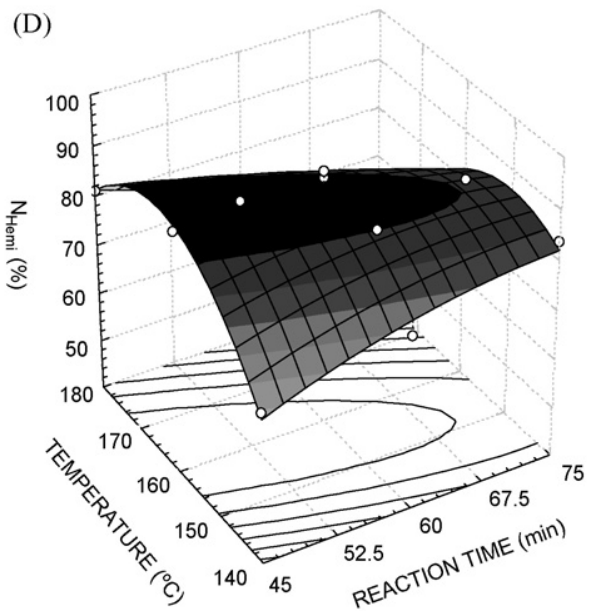

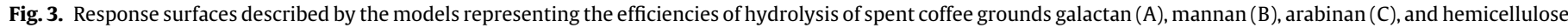
(D).

ature and reaction time (assay 4, Table 4). As a consequence of this high arabinose degradation, very low efficiency of hydrolysis of arabinan was obtained, corresponding to $29.4 \%$ only (assay 4 , Table 2 ). Besides furfural, other toxic compounds including hydroxymethylfurfural (HMF), acetic acid, and phenols were also found in SCG hydrolysates. Presence of these compounds is common in hemicellulosic hydrolysates produced by dilute acid hydrolysis (Mussatto \& Roberto, 2004).

The experimental results in Table 2 were used to estimate the main effects of the variables and their interactions on the efficiency of hydrolysis of SCG hemicellulose. The statistical analysis revealed a negative main effect $(p<0.05)$ of both, reaction time and temperature in this response. This means that the hemicellulose hydrolysis efficiency was increased when the reaction time and temperature were decreased. However, this behavior was not linear for the temperature, since the quadratic effect of this variable was also significant for this response at $95 \%$ confidence level. This means that the lowest temperature is not the most suitable for an efficient hemicellulose hydrolysis, but there is a region between 140 and $180^{\circ} \mathrm{C}$ where this response is maximized. A second-order polynomial is thus the most suitable to describe the variations of this response as a function of the temperature and reaction time.

Regression analyses were performed to fit the responses with the experimental data. When it was possible, the variables that were not significant (even at $90 \%$ confidence level) were excluded from the models. In other cases, the non-significant variables were kept in the models to minimize the error determination. Eqs. (7)-(10), where the variables take their coded values, represent the efficiency of hydrolysis of galactan $\left(\eta_{\text {Gal }}\right)$, mannan $\left(\eta_{\text {Man }}\right)$, arabinan $\left(\eta_{\text {Arab }}\right)$, and hemicellulose $\left(\eta_{\mathrm{Hemi}}\right)$, as a function of the reaction time $\left(X_{3}\right)$ and temperature $\left(X_{4}\right)$.

$$
\begin{aligned}
\eta_{\text {Gal }} \%= & 101.76-3.90 X_{3}-3.51 X_{3}^{2}-6.50 X_{4} \\
& -7.61 X_{4}^{2}-8.40 X_{3} X_{4} \quad\left(R^{2}=0.90\right)
\end{aligned}
$$

$$
\eta_{\text {Man }}(\%)=75.28-7.53 X_{3}-50.85 X_{4}^{2}
$$

$$
-29.15 X_{3} X_{4} \quad\left(R^{2}=0.93\right)
$$

$$
\begin{aligned}
\eta_{\text {Arab }}(\%)= & 90.91-16.08 X_{3}-9.51 X_{3}^{2}-24.00 X_{4} \\
& -9.16 X_{4}^{2}-12.53 X_{3} X_{4} \quad\left(R^{2}=0.89\right) \\
\eta_{\text {Hemi }}(\%)= & 85.10-8.83 X_{3}-9.80 X_{4}-36.60 X_{4}^{2} \\
& -24.30 X_{3} X_{4} \quad\left(R^{2}=0.96\right)
\end{aligned}
$$

The obtained models did not show lack-of-fit and presented high determination coefficients $\left(R^{2} \geq 0.89\right.$ ), explaining more than $89 \%$ of the variability in the responses. Three-dimensional response surfaces described by the models were plotted (Fig. 3). Note that the fitted surfaces have a non-linear region where the responses values are maximized (dark region). Based on the four obtained models, 


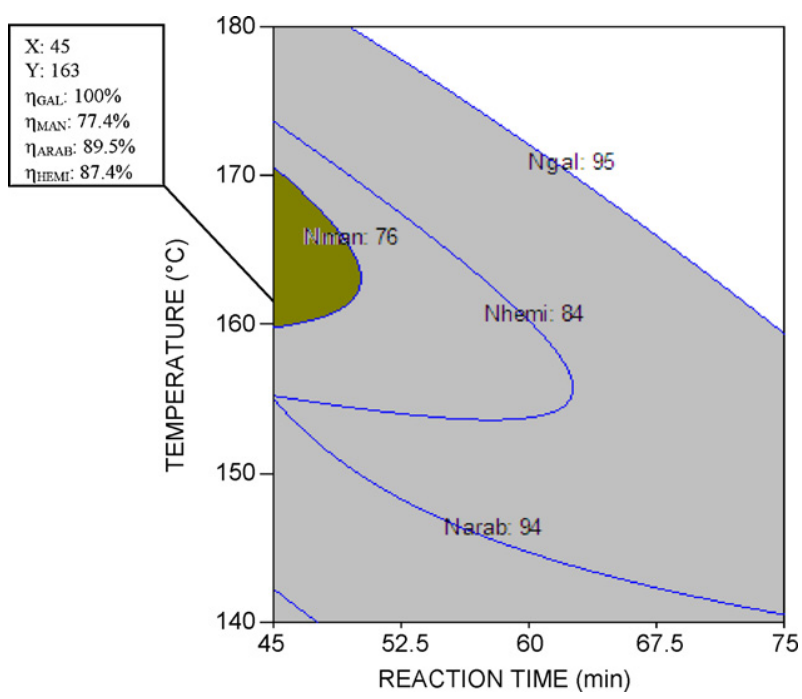

Fig. 4. Optimum region by overlay plots of the four responses (efficiency of hydrolysis of galactan $-\eta_{\text {gal }}$, mannan $-\eta_{\text {man }}$, arabinan $-\eta_{\text {arab }}$, and hemicellulose $-\eta_{\text {hemi }}$ ) as a function of the temperature and reaction time used for dilute acid hydrolysis of spent coffee grounds.

a graphical optimization was conducted using the 'Design expert' program. The method basically consists of overlaying the curves of all the models according to the criteria imposed. The optimal working conditions were defined to attain maximum hydrolysis efficiencies for galactan, mannan, arabinan, and hemicellulose. The criteria adopted were (a) galactan hydrolysis efficiency greater than $95 \%$, (b) mannan hydrolysis efficiency superior to $76 \%$, (c) arabinan hydrolysis efficiency higher than $94 \%$, and (d) hemicellulose hydrolysis efficiency greater than $84 \%$. The overlaying plot attained (Fig. 4) shows a dark area where all the criteria imposed were satisfied. A point was thus chosen in this area (marked by the square) where all the responses were maximum. This point was assigned as optimum point and corresponded to the use of temperature of $163^{\circ} \mathrm{C}$, and reaction time of $45 \mathrm{~min}$. Under these conditions, the model predicted hydrolysis efficiencies of $100 \%, 77.4 \%, 89.5 \%$, and $87.4 \%$ for galactan, mannan, arabinan, and hemicellulose, respectively.

\section{Conclusions}

SCG is an agro-industrial residue composed in the majority by carbohydrates, being mannose, galactose, and arabinose (from hemicellulose) and glucose (from cellulose), the main sugars present. Optimal conditions for hemicellulose sugars extraction by dilute acid hydrolysis were established, and consisted in using $100 \mathrm{mg}$ acid/g dry matter, $10 \mathrm{~g} / \mathrm{g}$ liquid-to-solid ratio, at $163^{\circ} \mathrm{C}$ for $45 \mathrm{~min}$. Under these conditions, hydrolysis efficiencies of $100 \%$, $77.4 \%, 89.5 \%$, and $87.4 \%$ can be achieved for SCG galactan, mannan, arabinan and hemicellulose, respectively. The hydrolysate produced under these optimal conditions is a promising source of sugars, which could be used in the production of several chemical compounds by chemical or fermentation processes. Mannose, for example, the main sugar obtained from SCG hydrolysis, could be used for the production of mannitol, a chemical with a wide variety of uses in the food industry.

\section{Acknowledgements}

NovaDelta-Comércio e Indústria de Cafés, S.A. (Campo Maior, Portugal).

\section{References}

Arya, M., \& Rao, L. J. M. (2007). An impression of coffee carbohydrates. Critical Reviews in Food Science and Nutrition, 47, 51-67.

Bradbury, A. G. W., \& Atkins, E. D. T. (1997). Factors affecting mannan solubility in roast coffee extracts. In Proceedings of ASIC conference, 17th colloquium Nairobi.

Bradbury, A. G. W., \& Halliday, D. J. (1990). Chemical structures of green coffee bean polysaccharides. Journal of Agricultural and Food Chemistry, 38, 389-392.

Delgado, P. A., Vignoli, J. A., Siika-aho, M., \& Franco, T. T. (2008). Sediments in coffee extracts: Composition and control by enzymatic hydrolysis. Food Chemistry, 110 $168-176$.

Fischer, M., Reimann, S., Trovato, V., \& Redgwell, R. J. (2001). Polysaccharides of green arabica and robusta coffee beans. Carbohydrate Research, 330, 93-101.

Franca, A. S., Oliveira, L. S., \& Ferreira, M. E. (2009). Kinetics and equilibrium studies of methylene blue adsorption by spent coffee grounds. Desalination, 249, 267 272.

Kondamudi, N., Mohapatra, S. K., \& Misra, M. (2008). Spent coffee grounds as a versatile source of green energy. Journal of Agricultural and Food Chemistry, 56, 11757-11760.

Lago, R. C. A., Antoniassi, R., \& Freitas, S. C. (2001). Composição centesimal e de aminoacidos de café verde, torrado e de borra de café soluvel. In 2 Simposio de Pesquisa dos Cafés do Brasil Vitoria, ES. Resumos, (p. 104).

Leifa, F., Pandey, A., \& Soccol, C. R. (2000). Solid state cultivation-An efficient method to use toxic agro-industrial residues. Journal of Basic Microbiology, 40, 187197.

Mussatto, S. I., \& Roberto, I. C. (2004). Alternatives for detoxification of diluted acid lignocellulosic hydrolyzates for use in fermentative processes: A review. Bioresource Technology, 93, 1-10.

Mussatto, S. I., \& Roberto, I. C. (2005). Acid hydrolysis and fermentation of brewer's spent grain to produce xylitol. Journal of the Science of Food and Agriculture, 85, 2453-2460.

Navarini, L., Gilli, R., Gombac, V., Abatangelo, A., Bosco, M., \& Toffanin, R. (1999). Polysaccharides from hot water extracts of roasted Coffea arabica beans: Isolation and characterization. Carbohydrate Polymers, 40, 71-81.

Neureiter, M., Danner, H., Frühauf, S., Kromus, S., Thomasser, C., Braun, R., et al. (2004). Dilute acid hydrolysis of presscakes from silage and grass to recove hemicellulose-derived sugars. Bioresource Technology, 92, 21-29.

Nunes, F. M., Reis, A., Domingues, M. R. M., \& Coimbra, M. A. (2006). Characterization of galactomannan derivatives in roasted coffee beverages. Journal of Agricultural and Food Chemistry, 54, 3428-3439.

Oosterveld, A., Harmsen, J. S., Voragen, A. G. J., \& Schols, H. A. (2003). Extraction and characterization of polysaccharides from and roasted Coffea arabica beans. Carbohydrate Polymers, 52, 285-296.

Ravindranath, R., Yousuf Ali Khan, R., Oby Reddy, T., Thirumala Rao, S. D., \& Reddy, B. R. (1972). Composition and characteristics of Indian coffee bean, spent ground and oil. Journal of the Science of Food and Agriculture, 23, 307-310.

Redgwell, R. J, Curti, D., Fischer, M., Nicolas, P., \& Fay, L. B. (2002). Coffee bean arabinogalactans: Acidic polymers covalently linked to protein. Carbohydrate Research, 337, 239-253.

Roberto, I. C., Mussatto, S. I., \& Rodrigues, R. C. L. B. (2003). Dilute-acid hydrolysis for optimization of xylose recovery from rice straw in a semi-pilot reactor. Industrial Crops and Products, 17, 171-176.

Saha, B. C. (2003). Hemicellulose bioconversion. Journal of Industrial Microbiology and Biotechnology, 30, 279-291.

Silva, M. A., Nebra, S. A., Silva, M. J. M., \& Sanchez, C. G. (1998). The use of biomass residues in the Brazilian soluble coffee industry. Biomass and Bioenergy, 14 457-467.

Simões, J., Madureira, P., Nunes, F. M., Domingues, M. R., Vilanova, M., \& Coimbra, M. A. (2009). Immunostimulatory properties of coffee mannans. Molecular Nutrition E' Food Research, 53, 1036-1043.

Tokimoto, T., Kawasaki, N., Nakamura, T., Akutagawa, J., \& Tanada, S. (2005). Removal of lead ions in drinking water by coffee grounds as vegetable biomass. Journal of Colloid and Interface Science, 281, 56-61.

Yen, W. J., Wang, B. S., Chang, L. W., \& Duh, P. D. (2005). Antioxidant properties of roasted coffee residues. Journal of Agricultural and Food Chemistry, 53 2658-2663. 